\title{
Clinical characteristics and patterns of healthcare utilization in patients with painful neuropathic disorders in UK general practice: a retrospective cohort study
}

\author{
Ariel Berger ${ }^{1}$, Alesia Sadosky², Ellen Dukes ${ }^{2}$, John Edelsberg $^{1}$ and Gerry Oster ${ }^{1 *}$
}

\begin{abstract}
Background: Clinical characteristics and patterns of healthcare utilization in patients with painful neuropathic disorders (PNDs) who are under the care of general practitioners (GPs) in the UK are not well understood.

Methods: Using a large electronic UK database, we identified all adults (age $\geq 18$ years) with any GP encounters between 1 January 2006 - 31 December 2006 at which a diagnosis of PND was noted ("PND patients"). An age-and gender-matched comparison group also was constituted consisting of randomly selected patients with one or more GP encounters-but no mention of PNDs-during this period. Characteristics and patterns of healthcare utilization of patients in the two groups were then examined over the one-year study period.

Results: The study sample consisted of 31,688 patients with mention of PNDs and an equal number of matched comparators; mean age was 56 years, and $62 \%$ were women. The prevalence of various comorbidities was higher among patients in the PND group, including digestive disorders (31\% vs. 17\% for comparison group), circulatory disorders (29\% vs. $22 \%$ ), and depression (4\% vs. 3\%) (all $p<0.01$ ). Receipt of prescriptions for pain-related pharmacotherapy also was higher among PND patients, including nonsteroidal anti-inflammatory drugs (56\% of PND patients had one or more such prescriptions vs. only $22 \%$ in the comparison group), opioids (49\% vs. $12 \%)$, tricyclic antidepressants ( $20 \%$ vs. $1 \%$ ), and antiepileptics ( $12 \%$ vs. $1 \%$ ) (all $p<0.01)$. PND patients also averaged significantly more GP visits (22.8 vs. 14.2) and referrals to specialists (2.8 vs. 1.4) over one year (both comparisons $p<0.01$ ).

Conclusions: Patients with PNDs under the care of GPs in the UK have relatively high levels of use of healthcare services and pain-related pharmacotherapy.
\end{abstract}

Keywords: Neuralgia, Nerve pain, Peripheral neuropathies, Pharmacotherapy, Analgesia, Health services research

\section{Background}

Neuropathic pain results from dysfunction of either the peripheral nerves or, less commonly, the central nervous system [1,2]. Neuropathic pain can be difficult to treat, and often requires the use of antiepileptic drugs (AEDs) and/or tricyclic antidepressants (TCAs) instead of-or in addition to-agents that are often used to treat nociceptive pain, such as nonsteroidal anti-inflammatory drugs (NSAIDs) and opioids. Previous guidelines for the treatment of painful neuropathies recommended a stepwise

\footnotetext{
* Correspondence: goster@pai2.com

'Policy Analysis Inc. (PAI), Four Davis Court Brookline, MA 02445, USA

Full list of author information is available at the end of the article
}

approach to treatment, with TCAs and/or AEDs used initially, followed by other agents (e.g., duloxetine, opioids) as needed. Pain clinics and/or psychological support also were recommended for patients whose pain remained inadequately controlled following multiple trials with different drugs $[3,4]$. Currently, TCAs, selected AEDs (i.e., gabapentin, pregabalin, carbamazepine), serotonin-norepinephrine reuptake inhibitor (SNRI) antidepressants (i.e., duloxetine, venlafaxine), and topical lidocaine are all recommended as first- and/or second-line therapy for pharmacologic management of painful neuropathies; tramadol and opioids are now recommended as second- and/or third-line therapy $[5,6]$. 
In contrast to the growing body of literature on the etiology, pathophysiology, and treatment of neuropathic pain, relatively little has been reported about the clinical characteristics and costs of patients with painful neuropathic disorders (PNDs) in clinical practice, including their levels of use of pain-related pharmacotherapy and healthcare services. These issues were examined by the authors in two prior studies in which patients with PNDs were compared with an equal number of age-and sex-matched comparators $[7,8]$. In the first study, 55,686 patients with PNDs in the US were identified during calendar-year (CY) 2000. In the second study, 275,685 patients with PNDs who were seen by general practitioners (GPs) in Germany between 1 August 2005 and 31 July 2006 were identified. In both studies, the prevalence of various comorbidities-including fibromyalgia, osteoarthritis, and depression-was much higher in patients with PNDs, as was the use of a range of painrelated medications, including opioids, AEDs, antidepressants, and benzodiazepines. Patients with PNDs received NSAIDs and opioids to a much greater extent than one would expect if treatment guidelines relevant for the time period of either study had been followed. Lachaine and colleagues used similar methods to examine the burden of PNDs among patients in Quebec [9]. Similar to findings reported for patients in the US and Germany, patients with PNDs $(n=4912)$ were reported to be more likely than their age- and gender-matched comparators to have comorbidities; they also had higher levels of use of pain-related medications, such as AEDs, antidepressants, opioids, and NSAIDs [9].

There is some evidence that patients with PNDs in the UK are similarly treated. In their study of approximately 25,000 patients with post-herpetic neuralgia, trigeminal neuralgia, phantom limb pain, or painful diabetic neuropathy newly diagnosed by a GP in the UK between CY1992 and CY2002, Hall et al. reported that the medications most commonly prescribed were amitriptyline, carbamazepine, coproxamol, codydramadol, and codeine + paracetamol [10]. In a second study that also focused on patients with these four PNDs in a UK GP database between May 2002 and July 2005, Hall et al. found that the most commonly prescribed drugs included TCAs, AEDs, and opioids [11]. A study by Gore and colleagues identified 30,999 patients with PNDs in a UK GP database in CY2001 (16,690 with pain predominantly neuropathic in nature ["pure"], and 14,309 with pain likely to have both nociceptive and neuropathic components ["mixed"]) [12]. Use of medications with proven efficacy in neuropathic pain (e.g., AEDs, TCAs) was reported to be low, although levels of use were higher in patients with "pure" versus "mixed" neuropathic pain. Many PND patients also had been prescribed agents that have not typically demonstrated efficacy in neuropathic pain (e.g., NSAIDs).

While providing important insights into the treatment of PNDs in the UK, these studies are not without their limitations. The two studies by Hall and colleagues were limited to the four above-noted PNDs; the degree to which their findings are generalizeable to the overall population of patients with PNDs is unknown. Moreover, none of these studies compared healthcare utilization and pharmacotherapy between patients with PNDs versus those without these disorders. We address this issue in the study described below, focusing attention on patients under the care of GPs in the UK.

\section{Methods}

Data were obtained from The Health Improvement Network (THIN) database, which consists of patient-level information on GP encounters from approximately 300 computerized GP practices throughout the UK. All practices registered with THIN use a clinical management system provided by In Practice Systems Ltd. (INPS). Many practices have contributed over 15 years of data to THIN, and more than 5 million patients are represented in the database. The database documents all patient care by GPs, and includes extensive information on diagnoses and treatments; it is designed to be representative of GP practices throughout the UK. All patient identifiers in the database are fully encrypted to protect patient confidentiality.

Available information in the THIN database includes date of service, diagnoses (in READ format), actions taken (e.g., referrals to other providers [i.e., specialists]), and medications prescribed-including the prescribing date and the quantity prescribed. Selected demographic information is also available, including patient age and gender. All patient-level data can be arrayed chronologically to provide a detailed, longitudinal profile of all medical and pharmacy services rendered by participating GPs.

The study protocol was submitted for review to-and subsequently approved by-the UK National Health Service (NHS) Multi-Centre Research Ethics Committee (MREC).

The study sample consisted of all patients, aged $\geq 18$ years, with one or more visits to GPs between 1 January 2006 and 31 December 2006 ("study period") (the most recent one-year period for which data were available at the time of study) at which a diagnosis of PND was noted (Appendix). A comparison group also was constituted, consisting of patients who did not have any GP encounters with noted diagnoses of PNDs during the same period; they were randomly selected and matched to PND patients based on age (within 1 year) and sex. 
(Patients in the comparison group could have other painful disorders, however, such as osteoarthritis and fibromyalgia.) All GP encounters were compiled for PND patients and patients in the comparison group over the 12-month study period.

The prevalence of selected clinically recognized comorbidities (e.g., arthritis, diseases of the circulatory system) was examined in both groups. Patients were deemed to have any of the conditions of interest if they had any encounters during the study period with a corresponding diagnosis code, or a prescription for a drug specific to that condition (e.g., diabetes was defined based on presence of corresponding [READ] diagnosis codes or prescriptions for any antidiabetic drugs).

The number of patients receiving prescriptions for pain-related and non-pain-related medications during the study period was examined. Medications were designated as "painrelated" based on their classification as analgesics or adjuvant medications in the World Health Organization's (WHO) “analgesic ladder” [13]. Although the WHO ladder was developed originally for cancer pain, the spectrum of pain-related medications also is used for the treatment of neuropathic pain [7,8,14-34]. Pain-related medications were defined to include: (1) AEDs; (2) benzodiazepines; (3) corticosteroids; (4) cyclooxygenase (COX)-2 inhibitors and other prescription NSAIDs; (5) muscle relaxants; (6) sedatives/hypnotics; (7) opioids (both short- and long-acting); (8) antidepressants (including TCAs, monoamine oxidase [MAO] inhibitors, and selective serotonin reuptake inhibitors [SSRIs]); (9) antimigraine agents; and (10) miscellaneous agents (injectable agents [e.g., bupivacaine], topical analgesics [e.g., lidocaine]). All other medications were designated non-pain-related.

Use of healthcare services during the 12-month study period was examined in terms of the numbers of GP visits, referrals from GPs to other healthcare providers (e.g., specialists), and hospitalizations; "sick notes" (physician-excused absences from work) also was examined. We did not attempt to attribute care specifically to the treatment of PNDs, because of inherent difficulties in attribution using electronic healthcare databases. We also did not attempt to examine nonpharmacologic treatments for PNDs, such as spinal cord stimulation and psychological support.

The statistical significance of differences in continuous measures between the PND and comparison groups was ascertained using paired t-tests or Wilcoxon signed-rank tests, as appropriate. McNemar's and Bowker's tests, as appropriate, were used to ascertain the statistical significance of differences in categorical measures. All analyses were conducted using PC-SAS ${ }^{\circledR}$ v.8.4 [35].

\section{Results}

We identified a total of 31,688 patients with one or more encounters at which PNDs were recorded between 1 December 2006 and 31 January 2006; a comparison group of the same size also was constituted, matched on age and gender. The most frequently noted PNDs were neuropathic back pain (46.4\% of all PND patients), nerve impingement syndromes (e.g., carpal tunnel syndrome) (14.1\%), and unspecified neuropathic pain (e.g., "neuritis, unspecified", "neuralgia unspecified") (9.7\%) (Table 1).

Mean (SD) age of patients in both groups was 56.1 (16.6) years, and $61.6 \%$ were women (Table 2 ). Nearly one-third of patients $(32.9 \%)$ were $\geq 65$ years of age. The prevalence of various comorbidities was higher among PND patients, including diseases of the respiratory system (33.1\% vs. $24.6 \%$, respectively), diseases of the digestive system (31.5\% vs. $17.3 \%)$, diseases of the circulatory system (28.6\% vs. $21.6 \%)$, depression $(4.3 \%$ vs. $2.6 \%)$, and anxiety (2.8\% vs. $1.7 \%)$ (all $p<0.01$ ). Approximately one in five PND patients (i.e., 23\%) had at least one encounter during the study period with a diagnosis of "symptoms, signs, and ill-defined conditions", compared with only $11.1 \%$ of patients in the comparison group $(p<0.01)$. Eighty-eight percent of patients with PNDs had two or more comorbidities noted by their GPs during the study period, versus $56.9 \%$ for the comparison group.

The number of patients who received prescriptions from their GPs for pain-related pharmacotherapy was approximately twice as high in the PND group than in the comparison group ( $82.9 \%$ vs. $43.4 \%$, respectively; $p$ $<0.01$ ), including "traditional" analgesics, such as NSAIDs and opioids, as well as "adjuvant" medications, such as AEDs, benzodiazepine, and tricyclic antidepressants (Table 3). The pain-related medications most commonly prescribed by GPs to patients with PNDs included NSAIDs (including COX-2 inhibitors) (56.5\% of PND patients vs. $22.3 \%$ in the comparison group), opioids (49.5\% vs. $13.8 \%$ ), antidepressants (primarily TCAs) (29.9\% vs. 9.6\%), benzodiazepines (13.0\% vs. $4.9 \%$ ), and AEDs (12.1\% vs. 0.9\%) (all $p<0.01$ ).

The number of patients receiving prescriptions for non-pain-related medications also was much higher in the PND group than in the comparison group, including general systemic anti-infectives (45.6\% vs. $34.6 \%$, respectively), ACE inhibitors (26.6\% vs. $16.8 \%)$, antiulcerants (e.g., acid pump inhibitors, H2 blockers) (23.7\% vs. $12.1 \%)$, dermatologicals (23.6\% vs. $17.1 \%)$, and cough and cold preparations $(21.1 \%$ vs. $16.4 \%)$ (all $p<0.01)$ (Table 4). Overall use of non-pain-related medications was substantially higher among PND patients versus patients in the comparison group-for example, $54.4 \%$ of 


\section{Table 1 Distribution of painful neuropathic disorders*}

\begin{tabular}{|c|c|}
\hline Painful neuropathic disorder & Patients with painful neuropathies $(\mathrm{N}=31,688)$ \\
\hline Diabetic neuropathy & $658(2.1)$ \\
\hline Diabetic neuropathy & $812(2.6)$ \\
\hline Back pain with neuropathic involvement & $14,689(46.4)$ \\
\hline Neck pain with neuropathic involvement & $589(1.9)$ \\
\hline Cancer with neuropathic pain & $0(0.0)$ \\
\hline Causalgia & $73(0.2)$ \\
\hline Phantom limb pain & $76(0.2)$ \\
\hline Trigeminal neuralgia & $965(3.0)$ \\
\hline Atypical facial pain & $702(2.2)$ \\
\hline \multicolumn{2}{|l|}{ Neuropathic pain, unspecified } \\
\hline Neuralgia unspecified & $1,737(5.5)$ \\
\hline Neuralgia, neuritis and radiculitis unspecified & $2(0.0)$ \\
\hline Neuralgia, neuritis or radiculitis NOS & $3(0.0)$ \\
\hline Neuritis unspecified & $70(0.2)$ \\
\hline Neuropathic pain & $698(2.2)$ \\
\hline Peripheral neuropathy & $573(1.8)$ \\
\hline Polyneuropathy unspecified & $2(0.0)$ \\
\hline Any of above & $3,085(9.7)$ \\
\hline \multicolumn{2}{|l|}{ Nerve impingement syndromes } \\
\hline Carpal tunnel syndrome & $548(1.7)$ \\
\hline CTS-Carpal tunnel syndrome & $3,379(10.7)$ \\
\hline Cubital tunnel syndrome & $20(0.1)$ \\
\hline Median nerve compression in forearm & $1(0.0)$ \\
\hline Meralgia paraesthetica & $302(1.0)$ \\
\hline Morton's metatarsalgia & $98(0.3)$ \\
\hline Morton's neuralgia & $74(0.2)$ \\
\hline Nerve root and plexus compressions in & $22(0.1)$ \\
\hline \multicolumn{2}{|l|}{ diseases EC } \\
\hline Tarsal tunnel syndrome & $9(0.0)$ \\
\hline Any of above & $4,453(14.1)$ \\
\hline \multicolumn{2}{|l|}{ Other } \\
\hline Acute infective polyneuritis & $0(0.0)$ \\
\hline Acroparaesthesia-Schultze's type & $0(0.0)$ \\
\hline Acroparaesthesia - unspecified & $0(0.0)$ \\
\hline Alcoholic polyneuropathy & $4(0.0)$ \\
\hline Burning feet syndrome & $31(0.1)$ \\
\hline C/O paraesthesia & $1,999(6.3)$ \\
\hline Hereditary and idiopathic peripheral neuropathy & $2(0.0)$ \\
\hline Hereditary or idiopathic peripheral neuropathy NOS & $11(0.0)$ \\
\hline Hereditary peripheral neuropathy & $2(0.0)$ \\
\hline Hereditary sensory neuropathy & $2(0.0)$ \\
\hline Inflammatory and toxic neuropathy & $6(0.0)$ \\
\hline Korsakov's alcoholic psychosis with peripheral neuritis & $0(0.0)$ \\
\hline Median nerve neuritis & $2(0.0)$ \\
\hline Mononeuritis lower limb & $7(0.0)$ \\
\hline Mononeuritis multiplex & $3(0.0)$ \\
\hline Mononeuritis of unspecified site NOS & $1(0.0)$ \\
\hline
\end{tabular}


Table 1 Distribution of painful neuropathic disorders* (Continued)

\begin{tabular}{|c|c|}
\hline Mononeuritis of upper limb and mononeuritis multiplex & $1(0.0)$ \\
\hline Mononeuritis upper limb NOS & $2(0.0)$ \\
\hline Nerve root and plexus disorders & $41(0.1)$ \\
\hline Nerve root or plexus disorder NOS & $8(0.0)$ \\
\hline Neuralgic amyotrophy & $6(0.0)$ \\
\hline Neuritis ulnar nerve & $9(0.0)$ \\
\hline Neuropathy in association with hereditary ataxia & $0(0.0)$ \\
\hline O/E-hyperaesthesia present & $20(0.1)$ \\
\hline O/E-paraesthesia in hands & $25(0.1)$ \\
\hline O/E-paraesthesia present & $2(0.0)$ \\
\hline Other idiopathic peripheral neuropathy & $2(0.0)$ \\
\hline Other idiopathic peripheral neuropathy NOS & $0(0.0)$ \\
\hline Other mononeuritis lower limb & $0(0.0)$ \\
\hline Other nerve root or plexus disorder & $2(0.0)$ \\
\hline Other toxic agent polyneuropathy & $0(0.0)$ \\
\hline Other toxic or inflammatory neuropathy & $0(0.0)$ \\
\hline Other upper limb mononeuritis & $1(0.0)$ \\
\hline Paraesthesia & $0(0.0)$ \\
\hline Parsonage-Aldren-Turner syndrome & $0(0.0)$ \\
\hline Peripheral neuritis in pregnancy & $0(0.0)$ \\
\hline Peripheral neuropathy-hereditary or idiopathic & $145(0.5)$ \\
\hline Policeman's disease & $2(0.0)$ \\
\hline Polyneuropathy & $23(0.1)$ \\
\hline Polyneuropathy due to drugs & $0(0.0)$ \\
\hline Polyneuropathy in disease NOS & $1(0.0)$ \\
\hline Polyneuropathy in disseminated lupus erythematosus & $0(0.0)$ \\
\hline Polyneuropathy in porphyria & $0(0.0)$ \\
\hline Polyneuropathy in rheumatoid arthritis & $0(0.0)$ \\
\hline Polyneuropathy in sarcoidosis & $0(0.0)$ \\
\hline Polyneuropathy in uraemia & $0(0.0)$ \\
\hline Polyneuropathy in vitamin B deficiency & $0(0.0)$ \\
\hline Radiculitis unspecified & $7(0.0)$ \\
\hline Ramsey-Hunt syndrome & $18(0.1)$ \\
\hline Toxic or inflammatory neuropathy NOS & $0(0.0)$ \\
\hline Ulnar neuritis & $139(0.4)$ \\
\hline Unspecified mononeuritis lower limb & $0(0.0)$ \\
\hline D paraesthesia & $1,756(5.5)$ \\
\hline X Polyneuropathy, unspecified & $1(0.0)$ \\
\hline X Inflammatory polyneuropathy, unspecified & $0(0.0)$ \\
\hline Any of above & $4,281(13.5)$ \\
\hline Any of above & $31,688(100.0)$ \\
\hline
\end{tabular}

the former group received prescriptions for three or more different types of non-pain-related medications during the study period, versus only $39.1 \%$ of the latter group.
Patients with PNDs averaged significantly more GP visits during the 12-month study (mean [95\% CI] $=22.8$ [22.6, 23.0] vs. $14.2[14.1,14.3]$ for comparison group; $p$ $<0.01$ ) (Table 5). They also had approximately twice as 
Table 2 Demographic and clinical characteristics of study subjects*

\begin{tabular}{|c|c|c|c|}
\hline & $\begin{array}{l}\text { Patients with painful neuropathies } \\
\qquad(\mathrm{N}=31,688)\end{array}$ & $\begin{array}{l}\text { Comparison group } \\
(\mathrm{N}=31,688)\end{array}$ & $P$-Value \\
\hline Characteristic & & & - \\
\hline \multicolumn{4}{|l|}{ Age group, years } \\
\hline $18-44$ & $8,621(27.2)$ & $8,621(27.2)$ & \\
\hline $45-54$ & $6,056(19.1)$ & $6,056(19.1)$ & \\
\hline $55-64$ & $6,577(20.8)$ & $6,577(20.8)$ & \\
\hline$\geq 65$ & $10,434(32.9)$ & $10,434(32.9)$ & \\
\hline Mean (SD) & $56.1(16.6)$ & $56.1(16.6)$ & - \\
\hline Sex & & & - \\
\hline Males & $12,178(38.4)$ & $12,178(38.4)$ & \\
\hline Females & $19,510(61.6)$ & $19,510(61.6)$ & \\
\hline \multicolumn{4}{|l|}{ Comorbidities } \\
\hline Infectious and parasitic diseases & $5,822(18.4)$ & $3,308(10.4)$ & $<0.01$ \\
\hline Neoplasms & $1,787(5.6)$ & $1,281(4.0)$ & $<0.01$ \\
\hline $\begin{array}{l}\text { Any endocrine, nutritional and metabolic diseases, and } \\
\text { immunity disorders }\end{array}$ & $10,699(33.8)$ & $7,604(24.0)$ & $<0.01$ \\
\hline Diseases of the blood and blood-forming organs & $2,487(7.8)$ & $1,507(4.8)$ & $<0.01$ \\
\hline Any anxiety & $897(2.8)$ & $547(1.7)$ & $<0.01$ \\
\hline Any depression & $1,365(4.3)$ & $827(2.6)$ & $<0.01$ \\
\hline Any disease of the nervous system and sense organs & $14,691(46.4)$ & $5,854(18.5)$ & $<0.01$ \\
\hline Any disease of the circulatory system & $9,071(28.6)$ & $6,837(21.6)$ & $<0.01$ \\
\hline Any disease of the respiratory system & $10,485(33.1)$ & $7,786(24.6)$ & $<0.01$ \\
\hline Any disease of the digestive system & $9,970(31.5)$ & $5,488(17.3)$ & $<0.01$ \\
\hline Any disease of the genitourinary system & $5,019(15.8)$ & $3,497(11.0)$ & $<0.01$ \\
\hline $\begin{array}{l}\text { Complications of pregnancy, childbirth, and the } \\
\text { puerperium }\end{array}$ & $325(1.0)$ & $241(0.8)$ & $<0.01$ \\
\hline Any disease of the skin and subcutaneous tissue & $9,773(30.8)$ & $7,136(22.5)$ & $<0.01$ \\
\hline \multicolumn{4}{|l|}{$\begin{array}{l}\text { Diseases of the musculoskeletal system and connective } \\
\text { tissue }\end{array}$} \\
\hline Back pain & $15,444(48.7)$ & $693(2.2)$ & $<0.01$ \\
\hline Cervical pain & $2,011(6.3)$ & $615(1.9)$ & $<0.01$ \\
\hline Arthritis & $2,116(6.7)$ & $1,203(3.8)$ & $<0.01$ \\
\hline Fibromyalgia & $76(0.2)$ & $11(0.0)$ & $<0.01$ \\
\hline Other body/joint pain & $10,481(33.1)$ & $3,832(12.1)$ & $<0.01$ \\
\hline Other & $1,993(6.3)$ & $917(2.9)$ & $<0.01$ \\
\hline $\begin{array}{l}\text { Any disease of the musculoskeletal system and } \\
\text { connective tissue }\end{array}$ & $23,529(74.3)$ & $6,233(19.7)$ & $<0.01$ \\
\hline Congenital anomalies & $81(0.3)$ & $44(0.1)$ & $<0.01$ \\
\hline \multicolumn{4}{|l|}{ Symptoms, signs, and ill- defined conditions } \\
\hline Fatigue & $16(0.1)$ & $12(0.0)$ & 0.45 \\
\hline Headache & $392(1.2)$ & $79(0.2)$ & $<0.01$ \\
\hline Chest pain & $387(1.2)$ & $216(0.7)$ & $<0.01$ \\
\hline Abdominal pain & $640(2.0)$ & $351(1.1)$ & $<0.01$ \\
\hline Anxiety-related symptoms & $0(0.0)$ & $0(0.0)$ & - \\
\hline Gastric-related symptoms & $3(0.0)$ & $1(0.0)$ & 0.32 \\
\hline Other & $6,420(20.3)$ & $2,989(9.4)$ & $<0.01$ \\
\hline Any symptoms, signs, and ill- & $7,320(23.1)$ & $3,507(11.1)$ & $<0.01$ \\
\hline defined conditions & & & \\
\hline
\end{tabular}


Table 2 Demographic and clinical characteristics of study subjects* (Continued)

\begin{tabular}{|c|c|c|c|}
\hline Any injury and poisoning & 2,991 (9.4) & $2,021(6.4)$ & $<0.01$ \\
\hline Any sleep disorder & $528(1.7)$ & $257(0.8)$ & $<0.01$ \\
\hline Any of above $e^{* *}$ & $31,447(99.2)$ & $24,768(78.2)$ & $<0.01$ \\
\hline Number of comorbidities** & & & $<0.01$ \\
\hline 0 & $241(0.8)$ & $6,920(21.8)$ & \\
\hline 1 & $3,632(11.5)$ & $6,757(21.3)$ & \\
\hline 2 & $4,617(14.6)$ & $5,648(17.8)$ & \\
\hline 3 & 4,883 (15.4) & $4,222(13.3)$ & \\
\hline$\geq 4$ & 18,315 (57.8) & $8,141(25.7)$ & \\
\hline
\end{tabular}

*Unless otherwise indicated, all values are number (\%).

**Excluding painful neuropathic disorders.

many referrals to specialists $(2.8[2.8,2.9]$ vs. $1.4[1.4$, $1.4])$ and hospitalizations $(0.2[0.2,0.2]$ vs. $0.1[0.1,0.1])$ (both $p<0.01$ ). A total of $16.5 \%$ of PND patients had one or more "sick notes" (i.e., physician-excused work absences) during the year, versus $7.0 \%$, of the comparison group.

\section{Discussion}

Over a 12-month period, patients with PNDs were approximately twice as likely to have been prescribed pain-related medications by their GPs than patients without evidence of these disorders $(83 \%$ vs. $43 \%$, respectively)-most commonly, NSAIDs and opioids. Despite the proven efficacy of antidepressants (especially, TCAs) in treating neuropathic pain, which has led to recommendations regarding their use as first-line therapy $[4-6,36,37]$, only $30 \%$ of PND patients received prescriptions for these agents, and only $12 \%$ had been prescribed AEDs. These patterns of medication prescribing may indicate that UK GPs may be more comfortable with "traditional" analgesics for the treatment of neuropathic pain, which may have been appropriate to some degree, given that evidence of efficacy of opioids in neuropathic pain was available during the study period [37-41]. (We also note that current treatment recommendations, which were promulgated after the end of our study period, list opioids as second- and/or thirdline options for neuropathic pain $[5,6]$.) On the other hand, we were unable to ascertain the number of patients who received TCAs and AEDs in the past and discontinued these medications due to adverse effects or lack of efficacy. We also note that back pain with neuropathic involvement-the most frequently noted PND ( $46 \%$ of all PND patients)-is often associated with both neuropathic and nociceptive pain; the latter often responds well to NSAIDs and/or opioids.

Patients with PNDs also had more GP encounters with diagnoses of other medical problems (e.g., digestive, circulatory, and respiratory disorders, depression, anxiety) compared with their age-and sex-matched peers without evidence of PND; they also had higher levels of use of non-pain-related medications, such as anti-ulcerants, systemic anti-infectives, and dermatologicals. Patients with PNDs averaged 10 additional GP office visits over 1 year, and twice as many specialist referrals and hospitalizations; $17 \%$ had at least one physician-excused absence from work versus as opposed to only $7.0 \%$ in the comparison group. Other studies of US and German patients have reported similar findings $[7,8]$.

While the precise reasons for these associations are unclear, a number of possible explanations come to mind. For one, some comorbid conditions may be etiologically related to PNDs-for example, diabetes, vascular complications thereof, and diabetic peripheral neuropathy-and such associations therefore are not unexpected. More generally, since neuropathic disorders are often chronic and difficult to treat, patients with PNDs may present more frequently to their GPs than patients without these disorders. More frequent visits may lead to more opportunistic case findings, and hence a higher rate of clinical recognition of many complaints and diseases that otherwise might have gone undiagnosed and/ or untreated. Difficulties in diagnosing neuropathic disorders also may have yielded spuriously high rates of comorbid conditions among PND patients. On the other hand, since THIN does not have a direct link to hospital data and/or sick notes, our findings may actually underestimate the prevalence of various comorbidities. Further study is needed to better understand how common these comorbidities are in patients with PNDs, as well as the relationship between these conditions and PNDs.

In their study utilizing another electronic database containing information from GP encounters in the UK, Gore and colleagues reported that NSAIDs were the most commonly dispensed medication among patients with "pure" PNDs (i.e., conditions in which pain was believed to be predominantly neuropathic in nature) 
Table 3 Use of pain-related medications among study subjects*

\begin{tabular}{|c|c|c|c|}
\hline & $\begin{array}{l}\text { Patients with painful neuropathies } \\
\qquad(\mathrm{N}=31,688)\end{array}$ & $\begin{array}{l}\text { Comparison group } \\
(\mathrm{N}=31,688)\end{array}$ & $P$-Value \\
\hline \multicolumn{4}{|l|}{ Number receiving } \\
\hline Antiepileptic drugs & $3,838(12.1)$ & $283(0.9)$ & $<0.01$ \\
\hline Benzodiazepines & $4,127(13.0)$ & $1,546(4.9)$ & $<0.01$ \\
\hline Corticosteroids & $3,297(10.4)$ & $1,563(4.9)$ & $<0.01$ \\
\hline \multicolumn{4}{|l|}{ Nonsteroidal anti- inflammatory drugs } \\
\hline Cyclooxygenase-2 inhibitors & $730(2.3)$ & $209(0.7)$ & $<0.01$ \\
\hline $\begin{array}{l}\text { Other nonsteroidal anti- inflammatory } \\
\text { drugs }\end{array}$ & $17,597(55.5)$ & $6,946(21.9)$ & $<0.01$ \\
\hline Any of above & $17,902(56.5)$ & $7,059(22.3)$ & $<0.01$ \\
\hline Muscle relaxants & $422(1.3)$ & $70(0.2)$ & $<0.01$ \\
\hline Sedatives/hypnotics & $1,548(4.9)$ & $749(2.4)$ & $<0.01$ \\
\hline \multicolumn{4}{|l|}{ Opioids } \\
\hline Short-acting opioids & $15,587(49.2)$ & 4,369 (13.8) & $<0.01$ \\
\hline Long-acting opioids & $719(2.3)$ & $66(0.2)$ & $<0.01$ \\
\hline Any of above & $15,674(49.5)$ & $4,388(13.8)$ & $<0.01$ \\
\hline \multicolumn{4}{|l|}{ Antidepressants } \\
\hline Tricyclic antidepressants & $6,320(19.9)$ & $477(1.5)$ & $<0.01$ \\
\hline Monoamine oxidase inhibitors & $12(0.0)$ & $7(0.0)$ & 0.25 \\
\hline Selective serotonin reuptake inhibitors & $3,397(10.7)$ & $2,259(7.1)$ & $<0.01$ \\
\hline Other antidepressants & $999(3.2)$ & $523(1.7)$ & $<0.01$ \\
\hline Any of above & $9,463(29.9)$ & $3,038(9.6)$ & $<0.01$ \\
\hline \multicolumn{4}{|l|}{ Antimigraine } \\
\hline Triptans & $480(1.5)$ & $268(0.8)$ & $<0.01$ \\
\hline Other antimigraine & $231(0.7)$ & $110(0.3)$ & $<0.01$ \\
\hline Any of above & $647(2.0)$ & $351(1.1)$ & $<0.01$ \\
\hline \multicolumn{4}{|l|}{ Miscellaneous } \\
\hline Injectable analgesics & $759(2.4)$ & $410(1.3)$ & $<0.01$ \\
\hline Topical analgesics & $4,258(13.4)$ & 2,502 (7.9) & $<0.01$ \\
\hline Other & $107(0.3)$ & $49(0.2)$ & $<0.01$ \\
\hline Any of above & $4,941(15.6)$ & 2,896 (9.1) & $<0.01$ \\
\hline Any of above & $26,265(82.9)$ & $13,745(43.4)$ & $<0.01$ \\
\hline Number receiving & & & $<0.01$ \\
\hline None of the above & $5,434(17.1)$ & $17,952(56.7)$ & \\
\hline 1 of the above & $7,877(24.9)$ & $8,047(25.4)$ & \\
\hline 2 of the above & $7,919(25.0)$ & $3,677(11.6)$ & \\
\hline 3 of the above & $5,264(16.6)$ & $1,368(4.3)$ & \\
\hline$\geq 4$ of above & $5,194(16.4)$ & $644(2.0)$ & \\
\hline Any of above & $26,265(82.9)$ & $13,745(43.4)$ & $<0.01$ \\
\hline
\end{tabular}

*Unless otherwise indicated, all values are number (\%).

(53\% of all identified patients with PNDs) [12]; 17\% received TCAs, $12 \%$ received AEDs, $11 \%$ received a second-generation antidepressants (e.g., SSRIs), and 9\% received opioids. We generally observed much higher levels of prescribing of these medications in our study, the only exception being NSAIDs. Of particular note, the number of PND patients who were prescribed opioids was almost fivefold higher in our study than that reported by Gore and colleagues. While the precise reasons for this difference are unclear, it may be due to differences in operational definitions of study measures (e.g., how combination products containing NSAIDs and opioids were classified) and/or differences in the study databases. Another possible reason may be changes in 
Table 4 Use of selected non-pain-related medications among study subjects*

\begin{tabular}{|c|c|c|c|}
\hline & $\begin{array}{l}\text { Patients with painful neuropathies } \\
\qquad(\mathrm{N}=31,688)\end{array}$ & $\begin{array}{l}\text { Comparison group } \\
(\mathrm{N}=31,688)\end{array}$ & $P$-Value \\
\hline \multicolumn{4}{|l|}{ Number receiving } \\
\hline General anti-infectives systemic & $14,451(45.6)$ & $10,953(34.6)$ & $<0.01$ \\
\hline Cough and cold preparations & $6,682(21.1)$ & $5,188(16.4)$ & $<0.01$ \\
\hline Dermatologicals & $7,464(23.6)$ & $5,415(17.1)$ & $<0.01$ \\
\hline ACE inhibitors & $8,421(26.6)$ & $5,327(16.8)$ & $<0.01$ \\
\hline Antiulcerants & $7,525(23.7)$ & $3,819(12.1)$ & $<0.01$ \\
\hline Beta-blocking agents & $6,148(19.4)$ & $4,446(14.0)$ & $<0.01$ \\
\hline Anti-asthma and COPD products & $5,534(17.5)$ & $3,450(10.9)$ & $<0.01$ \\
\hline Drugs used in diabetes & $4,553(14.4)$ & $3,996(12.6)$ & $<0.01$ \\
\hline Diuretics & $5,081(16.0)$ & $4,224(13.3)$ & $<0.01$ \\
\hline Plain antispasmodics and anticholinergics & $6,267(19.8)$ & $4,133(13.0)$ & $<0.01$ \\
\hline Thyroid therapy & $3,909(12.3)$ & $3,494(11.0)$ & $<0.01$ \\
\hline Calcium antagonists & $4,340(13.7)$ & $3,565(11.3)$ & $<0.01$ \\
\hline Statins & $4,377(13.8)$ & $1,900(6.0)$ & $<0.01$ \\
\hline $\begin{array}{l}\text { Antidiarrhoeals, oral electrolyte replacers and intestinal } \\
\text { anti-inflammatories }\end{array}$ & $3,336(10.5)$ & $2,116(6.7)$ & $<0.01$ \\
\hline Non-narcotics and anti-pyretics & $2,711(8.6)$ & $1,802(5.7)$ & $<0.01$ \\
\hline Respiratory system and nasal preparations & $2,558(8.1)$ & $1,722(5.4)$ & $<0.01$ \\
\hline Angiotensin-II antagonists & $2,532(8.0)$ & $1,764(5.6)$ & $<0.01$ \\
\hline Heparins & $2,412(7.6)$ & $1,573(5.0)$ & $<0.01$ \\
\hline Ophthalmologicals & $2,158(6.8)$ & $1,581(5.0)$ & $<0.01$ \\
\hline Urologicals & $2,614(8.2)$ & $1,406(4.4)$ & $<0.01$ \\
\hline Systemic antihistamines & $2,313(7.3)$ & $1,797(5.7)$ & $<0.01$ \\
\hline Anti-gout preparations & 2,305 (7.3) & $1,531(4.8)$ & $<0.01$ \\
\hline Nitrites and nitrates & $2,016(6.4)$ & $991(3.1)$ & $<0.01$ \\
\hline Mineral supplements & $2,173(6.9)$ & $1,393(4.4)$ & $<0.01$ \\
\hline Diagnostic agents & 2,201 (6.9) & $1,090(3.4)$ & $<0.01$ \\
\hline Number receiving & & & $<0.01$ \\
\hline None of the above & $5,114(16.1)$ & $8,329(26.3)$ & \\
\hline 1 of the above & $5,020(15.8)$ & 6,513 (20.6) & \\
\hline 2 of the above & 4,329 (13.7) & $4,460(14.1)$ & \\
\hline 3 of the above & $3,612(11.4)$ & $3,415(10.8)$ & \\
\hline$\geq 4$ of above & $13,613(43.0)$ & $8,971(28.3)$ & \\
\hline Any of above & 26,574 (83.9) & $23,359(73.7)$ & $<0.01$ \\
\hline
\end{tabular}

*Unless otherwise indicated, all values are number (\%)

ACE: Angiotensin-converting enzyme; COPD: Chronic obstructive pulmonary disease

practice and prescribing patterns that have occurred between the timeframes of the Gore et al. study (CY2001) and ours (CY2006), although the magnitude of difference seems too high to be explained by this factor alone.

Patterns of prescribing of pain-related pharmacotherapy among our study subjects also differed substantially from those reported by Hall and colleagues, who used the same database to examine patterns of pharmacotherapy among patients with post-herpetic neuralgia
$(\mathrm{N}=1923)$, trigeminal neuralgia $(\mathrm{N}=1862)$, phantom limb pain $(\mathrm{N}=57)$, and painful diabetic neuropathy ( $\mathrm{N}$ = 1444) between May 2002 and July 2005 [11]. Specifically, Hall et al. reported substantially higher percentages of patients receiving prescriptions for AEDs (32.5\% vs. $12.1 \%$ in our current study) and TCAs $(41.3 \%$ vs. 19.9\%); we observed higher percentages of patients receiving prescriptions for opioids $(49.5 \%$ vs. $29.1 \%$ in Hall et al.), NSAIDs (56.5\% vs. 30.6\% ["non-opioid analgesics"]), and other antidepressants $(10.0 \%$ vs. $3.7 \%)$. 
Table 5 Numbers of office visits, referrals, hospitalizations, and sick notes among study subjects*

\begin{tabular}{|c|c|c|c|}
\hline & Patients with painful neuropathies ( $N=31,688$ ) & Comparison group $(\mathrm{N}=31,688)$ & $P$-Value \\
\hline Number of office visits & & & $<0.01$ \\
\hline $0-5$ & $3,314(10.5)$ & $9,680(30.5)$ & \\
\hline $6-10$ & $4,489(14.2)$ & $5,892(18.6)$ & \\
\hline $11-15$ & $4,602(14.5)$ & $4,641(14.6)$ & \\
\hline $16-20$ & 4,295 (13.6) & $3,696(11.7)$ & \\
\hline$>20$ & $14,988(47.3)$ & $7,779(24.5)$ & \\
\hline Mean $(95 \% \mathrm{Cl})$ & $22.8(22.6-23.0)$ & $14.2(14.1-14.3)$ & $<0.01$ \\
\hline Median (IQR) & $19(11)$ & $11(4)$ & \\
\hline Minimum & 1 & 1 & \\
\hline Maximum & 356 & 362 & \\
\hline Number of referrals & & & $<0.01$ \\
\hline 0 & $11,136(35.1)$ & $17,875(56.4)$ & \\
\hline 1 & $5,751(18.1)$ & $5,256(16.6)$ & \\
\hline 2 & $3,664(11.6)$ & $2,641(8.3)$ & \\
\hline$\geq 3$ & $11,137(35.1)$ & $5,916(18.7)$ & \\
\hline Mean $(95 \% \mathrm{Cl})$ & $2.8(2.8-2.9)$ & $1.4(1.4-1.4)$ & $<0.01$ \\
\hline Median (IQR) & $1.0(0.0-4.0)$ & $0.0(0.0-2.0)$ & \\
\hline Minimum & 0 & 0 & \\
\hline Maximum & 55 & 65 & \\
\hline Number of hospitalizations & & & $<0.01$ \\
\hline 0 & $28,538(90.1)$ & $29,971(94.6)$ & \\
\hline 1 & $2,124(6.7)$ & $1,175(3.7)$ & \\
\hline 2 & $635(2.0)$ & $352(1.1)$ & \\
\hline$\geq 3$ & $391(1.2)$ & $190(0.6)$ & \\
\hline Mean $(95 \% \mathrm{Cl})$ & $0.2(0.2-0.2)$ & $0.1(0.1-0.1)$ & $<0.01$ \\
\hline Median (IQR) & $0.0(0.0-0.0)$ & $0.0(0.0-0.0)$ & \\
\hline Minimum & 0 & 0 & \\
\hline Maximum & 23 & 38 & \\
\hline Number of sick notes & & & $<0.01$ \\
\hline 0 & $26,453(83.5)$ & $29,474(93.0)$ & \\
\hline 1 & $2,046(6.5)$ & $1,111(3.5)$ & \\
\hline 2 & $1,109(3.5)$ & $505(1.6)$ & \\
\hline$\geq 3$ & $2,080(6.6)$ & $598(1.9)$ & \\
\hline Mean $(95 \% \mathrm{Cl})$ & $0.5(0.4-0.5)$ & $0.2(0.1-0.2)$ & $<0.01$ \\
\hline Median (IQR) & $0.0(0.0-0.0)$ & $0.0(0.0-0.0)$ & \\
\hline Minimum & 0 & 0 & \\
\hline Maximum & 19 & 19 & \\
\hline
\end{tabular}

*Unless otherwise indicated, all values are number (\%).

Cl confidence interval; IQR interquartile range

The biggest reason for this discrepancy is likely the sample selected-namely, Hall et al. focused on only four PNDs, while we included several other types of PNDs (e.g., back pain with neuropathic involvement, causalgia, nerve impingement syndromes).

Our study has several limitations. Perhaps most important, our findings are based on information from CY2006. Treatment guidelines changed after CY2006 and now recommend a number of different medications as first-line therapy for PNDs (e.g., TCAs, selected AEDs, selected SNRIs, topical lidocaine) [5,6]; the degree to which our findings represent current practice patterns in the UK is unknown.

Second, information on medication use was limited to drugs prescribed by GPs. Thus, to the extent that patients with PNDs (or those in the comparison group, 
Table 6 Painful neuropathic disorders

\begin{tabular}{|c|c|}
\hline & ICD-10 diagnosis codes \\
\hline \multicolumn{2}{|l|}{ Painful neuropathic disorders } \\
\hline \multicolumn{2}{|l|}{$\begin{array}{l}\text { "Pure" painful neuropathic } \\
\text { disorders }\end{array}$} \\
\hline Diabetic neuropathy & $\begin{array}{l}250 \text { AT, } 250 \text { F, C106.00, C106.11, C106.12, C106.13, C106000, C106100, C106y00, C106z00, C108200, C108211, } \\
\text { C108212, C108B00, C108B11, C108B12, C108C00, C108C11, C108C12, C108J00, C108J11, C108J12, C109200, C109211, } \\
\text { C109212, C109A00, C109A11, C109A12,C109B00, C109B11, C109B12, C10A400, C10E200, C10E211, C10E212, C10F200, } \\
\text { C10F211, C10FH00, C10FH11, F345000, F35z000, F372.00, F372.11, F372.12, F372000, F372100, F381311, F3y0.00 }\end{array}$ \\
\hline Post-herpetic neuralgia & 054 G, 355 PH, A531.11, A531200, A531300, A531500, A531511, F300.00, F374400 \\
\hline $\begin{array}{l}\text { Back pain with neuropathic } \\
\text { involvement }\end{array}$ & $\begin{array}{l}\text { 352, 7286, 3499E, } 353 \text { A, } 353 \text { C, } 353 \text { HP, } 353 \text { NP, } 353 \text { NT, } 353 \text { PP, } 353 \text { T, } 355 \text { AR, } 355 \text { AT, 7251D, 7285A, 7288LM, } \\
\text { 7288RP, 7289B, 7289CE, F161400, F163.00, F163000, F163200, F163z00, F16y.00, F16y000, F16y100, F16yz00, F16z.00, } \\
\text { F16z.11, F16z.12, F246.00, F246000, F246100, F246z00, F29y400, F29y411, F337100, F337200, F337200, F337300, } \\
\text { F350.00, F378.00, N113.00, N113000, N113100, N113200, N115.00, N115000, N115100, N115200, N11B.00, N11B000, } \\
\text { N11B100, N11B200, N11C.00, N11C000, N11C100, N11C200, N11y200, N11z100, N129.00, N129.11, N129000, } \\
\text { N129200, N129300, N129z00, N12B.00, N12B100, N12B200, N12C400, N134.11, N142000, N143.00, N143.11, N144.00, } \\
\text { N144.00, N144000, N144100, N144z00, N144z00, Nyu6200, Nyu6300, Nyu7300, Nyu7400 }\end{array}$ \\
\hline $\begin{array}{l}\text { Neck pain with neuropathic } \\
\text { involvement }\end{array}$ & $\begin{array}{l}\text { 7284, } 3470 \text { CE, } 352 \text { CS, } 355 \text { AS, } 357 \text { J, F330300, N111.00, N111000, N111100, N111200, N111300, N119.00, N119000, } \\
\text { N119100, N119200, N129100, N12B000, N12zH00, N134.00, N134.12, N134.12 }\end{array}$ \\
\hline Cancer with neuropathic pain & F337000, F373.00, Fyu7400 \\
\hline Causalgia & 355 CL, F344.00, N337.12, N337111 \\
\hline Phantom limb pain & 7816PL, 7816PM, 7816PN, F336.00, F336000 \\
\hline Trigeminal neuralgia & $\begin{array}{l}\text { 1475.00, 7021400, 7023000, 7024400, 7024411, 7025400, 7027400, 7028400, 7028511, } 351 \text { A, } 355 \text { JW, } 357 \text { H, F301.00, } \\
\text { F301000, F301z00, Fyu6000 }\end{array}$ \\
\hline Atypical facial pain & 351 AF, 351 BA, F302.00, F321.00 \\
\hline Other painful neuropathies & $\begin{array}{l}\text { 1B46.00, } 261 \text { BR, } 276 \text { NR, 29B4.00, 29B5.00, 29B5000, 3479DT, } 351 \text { OC, } 7871 \text { HA, } 7871 \text { HB, } 792 \text { N, } 792 \text { PN, A531111, } \\
\text { A72x100, C262300, C34y400, F335.00, F335.11, F342.11, F342000, F370100, F370z00, FyuAE00, G73y400, G73y411, } \\
\text { G73y500, G73y511, G73y600, R020700, 340.12, 352, 355.00, 357, 7283, 7288, 3032R, 3039PN, 3499M, } 352 \text { L, } 352 \text { LN, } \\
354 \text { P, } 355 \text { A, } 355 \text { AB, } 355 \text { AQ, } 355 \text { AV, } 355 \text { B, 355 C, 355D, 357 C, } 357 \text { K, } 357 \text { KL, } 357 \text { KP, } 357 \text { LN, } 357 \text { ME, } 357 \text { NL, } \\
\text { 357T, } 7283 B R, 7284 R P, 984 \text { N, 9851N, 9909ML, 'E011100, F33..00, F337.00, F33y.00, F33z.00, F34..00, F340.00, F340.12, } \\
\text { F341000, F341100, F345.00, F34y.00, F34z.00, F35..00, F351.00, F355.00, F356000, F356100, F356100, F35x.00, F35y.00, } \\
\text { F35z.00, F35z.11, F36.00, F360.00, F360z00, F362.00, F364.00, F365.00, F366.00, F367.00, F36y.00, F36yz00, F36z.00, } \\
\text { F37.00, F37..11, F370.00, F371.00, F371000, F371100, F371200, F371z00, F374.00, F374000, F374100, F374200, } \\
\text { F374300, F374500, F374600, F374700, F374800, F374900, F374A00, F374z00, F375.00, F376.00, F377.00, F37x.00, } \\
\text { F37y.00, F37y000, F37z.00, F37z.11, Fyu1300, Fyu6.00, Fyu6500, Fyu6A00, Fyu6B00, Fyu6C00, Fyu6D00, Fyu7.00, } \\
\text { Fyu7100, Fyu7200, Fyu7300, Fyu7500, Fyu7600, Fyu7700, Fyu7800, Fyu7900, Fyu7B00, Fyu7C00, FyuAC00, L164.00, } \\
\text { L164000, L164200, L164300, L164400, L164z00, N134.14, N1y0.00, N1y0.00, N242.00, N242000, N242100, N242200, } \\
\text { N242300, N242z00, N242z11 }\end{array}$ \\
\hline
\end{tabular}

for that matter) used medications available for direct retail purchase (i.e., without a prescription) and/or received "private prescriptions" (i.e., prescriptions wholly paid for by the patient (as opposed to the NHS), we may have underestimated total medication use.

Third, we do not know the reason(s) why particular medications were prescribed (e.g., for the treatment of PNDs or for pain associated with other conditions). Since some medications designated as "pain-related" also may be used to treat conditions that are not typically associated with pain (e.g., AEDs and seizure disorders, antidepressants and depression), it would be incorrect to infer that these agents were used exclusively for the treatment of neuropathic pain. However, only $4 \%$ of PND patients-and 3\% of those in the comparison group-had any encounters at which a diagnosis of depression was recorded; corresponding values for epilepsy were $0.2 \%$ and $0.1 \%$, respectively (data not shown). Similarly, given the widespread prevalence of comorbid pain-related conditions among patients with PNDs, as well as the possibility of "mixed" pain (i.e., neuropathic and nociceptive) among those with back pain with neuropathic involvement, it is possible that NSAIDs (and other pain-related medications for that matter) may have been prescribed for the treatment of pain that was not neuropathic in origin (e.g., triptans for migraine headache). Since we did not have access to medical records, the degree to which this actually occurred must remain conjectural.

Fourth, the study database is limited to information from GP encounters. Given the large numbers of PND patients with medical and psychiatric comorbidities-as well as the difficulty of treating PNDs-it is reasonable to expect that some patients in the study sample also had encounters with healthcare providers other than GPs.

Fifth, the GP-centric records of referrals, sick notes, and hospitalizations that are available in the study database are complete only to the extent that GPs actually 
record such information; to the extent that this information is not recorded by GPs, our findings may represent underestimates of healthcare utilization and prescribing patterns in this population.

Sixth, study subjects were selected based on evidence of at least one GP encounter during which a diagnosis of a PND was recorded during the one-year study period. Thus, patients who were exclusively under the care of specialists (e.g., neurologists, pain specialists) for their neuropathic pain, but who saw GPs for other reasons, would not necessarily have had GP encounters at which PNDs were noted. Not only would these patients not have been designated as having PNDs, but they also could have been selected for inclusion in the comparison group. On the other hand, the database does not contain information on how physicians rendered their diagnoses. Given that some types of PNDs are more difficult to diagnosis than others [42-44], and others are not exclusively neuropathic in origin (e.g., atypical facial pain) [45], it is possible that we may have misclassified some patients as having PNDs who in fact suffered from nociceptive pain. Unfortunately, since the database does not contain information that would shed light on these issues, the nature and extent of any misclassification that might have occurred is unknown.

\section{Conclusions}

Patients with PNDs under the care of GPs in the UK have relatively high levels of use of healthcare services and pain-related (and other) pharmacotherapy. Because treatment guidelines evolved while our study was underway, it is unknown whether patterns of pharmacotherapy that we observed are representative of clinical practice in the UK today.

\section{Disclosures}

This research was funded by Pfizer Inc., New York, NY. Mr. Berger, Dr. Edelsberg, and Dr. Oster are employed by Policy Analysis Inc., an independent contract research organization. Dr. Dukes is a former employee of Pfizer Inc. Dr. Sadosky is currently employed by Pfizer Inc.

\section{Appendix}

Table 6 sets forth all diagnoses (in READ format) used to identify patients with painful neuropathic disorders.

\section{Acknowledgements \\ Funding for this research was provided by Pfizer Inc., New York, NY. The authors are also indebted to Sophia Zilber, M.A., who assisted in the statistical programming required for the analyses.}

\section{Author details}

${ }^{1}$ Policy Analysis Inc. (PAI), Four Davis Court Brookline, MA 02445, USA. ${ }^{2}$ Pfizer Inc, 235 East 42nd Street, New York, NY 10017, USA.

\section{Authors' contributions}

All authors ( $A B, A S, E D, J E$ and $G O$ ) helped with all aspects of this study (i.e., conceptualization and design of study, analysis and interpretation of data, manuscript preparation and review). All authors read and approved the final manuscript.

\section{Competing interests}

Funding for this research was provided by Pfizer Inc., New York, NY. Two of the study authors-Dr. Sadosky, an employee of Pfizer Inc., and Dr. Dukes, an employee of Pfizer at the time this research was conducted-were involved with the design of the study, data analysis and interpretation, manuscript preparation, and publication decisions. Mr. Berger, Dr. Edelsberg, and Dr. Oster, who are employed by Policy Analysis Inc., were involved with the design of the study, data analysis and interpretation, manuscript preparation and publication decisions. Policy Analysis Inc. received funding to support manuscript development.

Received: 19 September 2011 Accepted: 6 March 2012 Published: 6 March 2012

\section{References}

1. Fields HL, Martin JB: Pain: pathophysiology and management. In Harrison's Principles of Internal Medicine.. 14 edition. Edited by: Fauci AS, Braunwald E, Isselbacher KJ, Wilson JD, Martin JB, Kasper DL, Hauser SL, Longo DL. United States of America: McGraw-Hill Companies; 1997:55-58.

2. Merskey H, Bogduk N: Classification of Chronic Pain: Descriptions of Chronic Pain Syndromes and Definitions of Pain Terms. 2 edition. Seattle: IASP Press; 1994

3. National Collaborating Centre for Chronic Conditions: Type 2 diabetes: national clinical guideline for management in primary and secondary care (update).[http://www.nice.org.uk/nicemedia/pdf/ CG66diabetesfullguideline.pdf].

4. Attal N, Cruccu G, Haanpaa M, Jensen TS, Nurmikko T, Sampaio C, Sindrup S, Wiffen P: EFNS guidelines on pharmacological treatment of neuropathic pain. Eur J Neurol 2006, 13:1153-1169.

5. O'Connor AB, Dworkin RH: Treatment of neuropathic pain: An overview of recent guidelines. Am J Med 2009, 122:S22-S32

6. Attal N, Finnerup NB, on behalf of the IASP Neuropathic Pain Special Interest Group (NeuPSIG): Pharmacological management of neuropathic pain. IASP 2010, 18:1-8.

7. Berger A, Dukes EM, Oster G: Clinical characteristics and economic costs of patients with painful neuropathic disorders. J Pain 2004, 5:143-149.

8. Berger A, Toelle T, Sadosky A, Dukes E, Edelsberg J, Oster G: Clinical and economic characteristics of patients with painful neuropathic disorders in Germany. Pain Practice 2009, 9:8-17.

9. Lachaine J, Gordon A, Choiniere M, Collet JP, Dion D, Tarride JE: Painful neuropathic disorders: an analysis of the Regi de l'Assurance Maladie du Quebec database. Pain Res Manage 2007, 12:31-37.

10. Hall GC, Carroll D, Parry D, McQuay HJ: Epidemiology and treatment of neuropathic pain: the UK primary care perspective. Pain 2006, 122:156-162.

11. Hall GC, Carroll D, McQuay HJ: Primary care incidence and treatment of four neuropathic pain conditions: a descriptive study, 2002-2005. BMC Fam Pract 2008, 9:26.

12. Gore M, Dukes E, Rowbotham DJ, Tai KS, Leslie D: Clinical characteristics and pain management among patients with painful peripheral neuropathic disorders in general practice settings. Eur J Pain 2007, 11:652-664.

13. World Health Organization: Cancer Pain Relief Geneva, Switzerland; 1996.

14. Allen RR: Neuropathic pain in the cancer patient. Neurol Clin 1998, 16:869-888.

15. Arner S, Meyerson BA: Lack of analgesic effect of opioids on neuropathic and idiopathic forms of pain. Pain 1988, 33:11-23.

16. Backonja M, Beydoun A, Edwards KR, Schwartz SL, Fonseca V, Hes M, LaMoreaux L, Garofalo E: Gabapentin for the symptomatic treatment of painful neuropathy in patients with diabetes mellitus: a randomized controlled trial. JAMA 1998, 280:1831-1836.

17. Backonja MM: Anticonvulsants (antineuropathics) for neuropathic pain syndromes. Clin J Pain 2000, 16:S67-S72.

18. Bonezzi C, Demartini L: Treatment options in postherpetic neuralgia. Acta Neurol Scand Suppl 1999, 173:25-35. 
19. Brant JM: Cancer-related neuropathic pain. Nurse Pract Forum 1998, 9:154-162.

20. Berger A, Dukes E, Mercadante S, Oster G: Use of antiepileptics and tricyclic antidepressants in cancer patients with neuropathic pain. Eur $J$ Cancer Care 2006, 15:138-145.

21. Carrazana E, Mikoshiba I: Rationale and evidence for the use of oxcarbazepine in neuropathic pain. J Pain Symptom Manage 2003, 25: S31-S35.

22. Cohen $\mathrm{KL}$, Harris S: Efficacy and safety of nonsteroidal anti-inflammatory drugs in the therapy of diabetic neuropathy. Arch Intern Med 1987, 147:1442-1444.

23. Farrar JT, Portenoy RK: Neuropathic cancer pain: the role of adjuvant analgesics. Oncology 2001, 15:1435-1445.

24. George RM, Ahmedzai SH: The management of neuropathic pain in cancer: clinical guidelines for the use of adjuvant analgesics. Indian J Cancer 2000, 37:4-9.

25. Green MW, Selman JE: Review article. The medical management of trigeminal neuralgia. Headache 1991, 31:588-592.

26. Hemstreet B, Lapointe M: Evidence for the use of gabapentin in the treatment of diabetic peripheral neuropathy. Clin Ther 2001, 23:520-531.

27. Kanner R: Diagnosis and management of neuropathic pain in patients with cancer. Cancer Invest 2001, 19:324-333.

28. Katz N: Neuropathic pain in cancer and AIDS. Clin J Pain 2000, 16:S41-S48

29. Max MB: Treatment of post-herpetic neuralgia: antidepressants. Ann Neurol 1994, 35:S50-S53.

30. McQuay H, Carroll D, Jadad AR, Wiffen P, Moore A: Anticonvulsant drugs for management of pain: a systematic review. BMJ 1995, 311:1047-1052.

31. Oster G, Berger A, Dukes E, Edelsberg J, McCarberg B: Use of potentially inappropriate pain-related medications in older adults with painful neuropathic disorders. Am J Geriatr Pharmacother 2004, 2:163-170.

32. Ripamonti C, Dickerson ED: Strategies for the treatment of cancer pain in the new millennium. Drugs 2001, 61:955-977.

33. Thompson M, Bones M: Nontraditional analgesics for the management of postherpetic neuralgia. Clin Pharm 1985, 4:170-176.

34. Volmink J, Lancaster T, Gray S, Silagy C: Treatments for postherpetic neuralgia-a systematic review of randomized controlled trials. Fam Pract 1996, 13:84-91.

35. SAS ${ }^{\circledR}$ Proprietary Software, Release 8.4. Cary, NC: SAS Institute Inc.

36. Gilron I, Watson DPN, Cahill CM, Moulin DE: Neuropathic pain: a practical guide for the clinician. CMAJ 2006, 175:265-275.

37. Mendell JR, Sahenk Z: Painful sensory neuropathy. N Eng J Med 2003 348:1243-1255.

38. Watson CPN, Babul N: Efficacy of oxycodone in neuropathic pain: a randomized trial in postherpetic neuralgia. Neurologia 1998, 50:1837-1841.

39. Rowbotham MC, Twilling L, Davies PS, Reisner L, Taylor K, Mohr D: Oral opioid therapy for chronic peripheral and central neuropathic pain. $N$ Engl J Med 2003, 348:1223-1232.

40. Harati Y, Gooch C, Swenson M, Edelman S, Greene D, Raskin P, Donofrio P, Cornblath D, Sachdeo R, Siu CO, Kamin M: Double-blind randomized trial of tramadol for the treatment of the pain of diabetic neuropathy. Neurology 1998, 50:1842-1846.

41. Sindrup SH, Jensen TS: Efficacy of pharmacological treatments of neuropathic pain: an update and effect related to the mechanism of drug action. Pain 1999, 83:389-400.

42. Hans G, Masquelier E, De Cock P: The diagnosis and management of neuropathic pain in daily practice in Belgium: an observational study. BMC Pub Health 2007, 170, doi:10.1186/1471-2458-7-170.

43. Chong MS, Bajwa ZH: Diagnosis and treatment of neuropathic pain. $J$ Pain Symptom Manage 2003, 25:S4-S11.

44. Williams $\mathrm{H}$ : Assessing, diagnosing and managing neuropathic pain. Nurs Times 2006, 102:22-24.

45. Forssell H, Tenovuo O, Silvoniemi P, Jaaskelainen SK: Differences and similarities between atypical facial pain and trigeminal neuropathic pain. J Neurophysiol 2008, 99:2251-2263.

\section{Pre-publication history}

The pre-publication history for this paper can be accessed here:

http://www.biomedcentral.com/1471-2377/12/8/prepub doi:10.1186/1471-2377-12-8

Cite this article as: Berger et al:: Clinical characteristics and patterns of healthcare utilization in patients with painful neuropathic disorders in UK general practice: a retrospective cohort study. BMC Neurology 2012

\section{Submit your next manuscript to BioMed Central and take full advantage of:}

- Convenient online submission

- Thorough peer review

- No space constraints or color figure charges

- Immediate publication on acceptance

- Inclusion in PubMed, CAS, Scopus and Google Scholar

- Research which is freely available for redistribution

Submit your manuscript at www.biomedcentral.com/submit
Biomed Central 